\title{
Problems and solutions in the field of improving control and supervision activities in the construction sector
}

\author{
Varvara Dikareva ${ }^{1, *}$ and Anna Mostovaya ${ }^{1}$ \\ ${ }^{1}$ Moscow State University of Civil Engineering, Yaroslavskoye shosse 26, Moscow, 129337, Russia
}

\begin{abstract}
The improvement of control and supervision activities in highrise construction is an important goal of the state. In the paper, the author considered the initiatives of the state in terms of improving the control activity. He shows the main approaches that will be applied by the state. The application of information and communication technologies in control activities is described in detail. It was noted that the quality of the regulation of various procedures remains a serious issue. At the same time, modern innovations in the field of control should take into account the increasing volumes of data and information about various economic processes.
\end{abstract}

\section{Introduction}

Control and supervision activities in the construction sector performs an important function. The state exercises control and pursues several goals. First, it is necessary to ensure correctness of drafting of all documentation in order to exclude material, physical and other damage during construction of the facility and its commissioning. Second, it is necessary to assess the effectiveness of the overall design activity in construction in order to adjust the system of measures of sectoral management. The main function in control and supervision activities is performed by the Ministry of Construction of Russia and various controlling state bodies, including the Accounts Chamber of the Russian Federation. Also, control is exercised independently by business entities. The basic requirements of control and supervision activities of the Ministry of Construction of Russia were established on the basis of the federal program "Reform of Control and Supervision Activities" approved on December 21, 2016 by the Presidium of the Council under the President of the Russian Federation for Strategic Development and Priority Projects. The implementation period is until 2025. Directly the Ministry of Construction of Russia, as a federal executive body which exercises normative and legal regulation in the areas of exercising control and supervision functions in terms of regional types of control (supervision), is a participant in this program. The totality of measures contained in this federal program has not only a large quantitative composition. Achievements of four levels are also provided. Analysis of the situation in practice shows that various violations continue to manifest themselves in the

\footnotetext{
* Corresponding author: dikareva-va@rambler.ru
} 
construction industry $[1,2,3]$. At the same time, active actions on the part of the authorities can have a positive result if the proposed solutions are subjected to a serious expert assessment and fully comply with the trends of the time.

\section{Materials and Methods}

Many levels of state administration of the industry, as well as the complexity of the projects themselves, their specific diversity create barriers to the creation and adequate application of effective management methods, regulation of all works, etc. [4]. Regulations, instructions, guidelines, methodical documents remain the main instrument of the state when exercising control and supervision activities. For business, the poor elaboration of government regulatory documents means the emergence of unforeseen temporary and financial costs. The authorities at the level of the constituent entities of the Russian Federation, as well as at the federal level, can not directly receive qualitative feedback for assessing their own managerial functions. The totality of regulatory and legal documents at the federal level comprehensively enough disclose the content of managerial functions and tools. At the same time, certain practical implementation at the level of the subjects of the Russian Federation and municipal bodies is significantly out of sync. As a result, formation of new regulatory and legal documents at the federal level is also subsequently implemented with obviously lower efficiency than expected. Fig. 1 shows the problematic issues in terms of control and supervision activities, and solutions that are implemented at the federal level, but which, among other things, will be aimed at solving problems in the construction sector.

This concept aims to increase the level of awareness of the executive authorities and their officials about the objects of control, their condition, and ensure effective planning of resources for performing control and supervision measures. For business representatives, it will be possible to quickly and in the medium term see the composition of control measures addressed to them, decisions made by state bodies on the basis of inspection findings and other information. At the same time, the industry still has a set of systemic problems that will impede the introduction of new control and management mechanisms.

Based on the foregoing, it is possible to state systemic limitations on the effectiveness of investment activities as part of administrative and market regulatory mechanisms. At the state level, they are as follows:

- Firstly, the low level of organization of work at the level of executive bodies;

- Secondly, the lack of a unified system for planning the activities of the authorities in terms of control and supervision;

- Thirdly, low efficiency of the feedback system, inconsistency of the system of normative legal documents being developed with tasks that require priority solving.

For business it is:

- Firstly, the lack of exhaustive regulations on interaction with authorities;

- Secondly, high risks of conducting supervised activities without a clear understanding of the rules and requirements;

- Thirdly, the lack of feedback regarding evaluation of the effectiveness of state control measures;

- Fourthly, low responsibility of state bodies for actions restricting entrepreneurial activity without availability of reasons. 
IMPLEMENTATION OF CONTROL AND SUPERVISORY ACTIVITIES

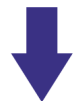

The federal authority (Minstroy of Russia)

Situation on the ground (subject, municipality)

\section{SYSTEMIC PROBLEMS}

of the executive authority in the field construction activities:

Отсутствие регламентов проведения проверок

The control over the execution of powers by local self-government bodies is not exercised sufficiently
Inconsistency of the state body's organizational structure

Lack of sufficient administrative regulations of the state body

Not all services are provided with information on the possibility of obtaining them
Inconsistency of ways and forms of submission of documents in state bodies by business representatives

\begin{tabular}{|c|}
\hline Lack of standards \\
for \\
urban planning
\end{tabular}

The order of application of the rules of land use is not disclosed

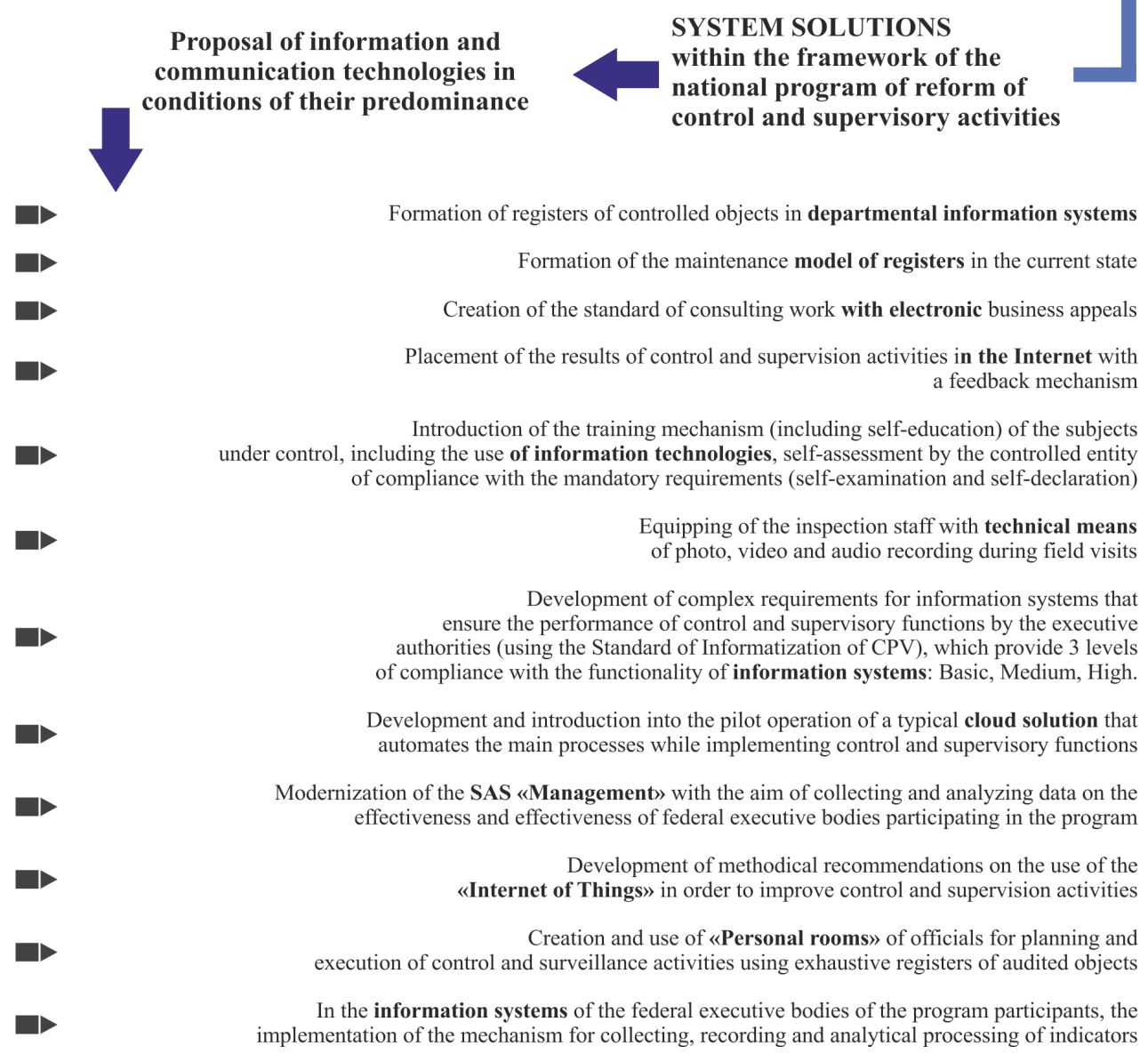

Fig. 1. Problems and solutions in the field of control and supervision activities. 
Taking into account the information in Fig. 1, it should be noted that in the future the state sees the use of information technology tools as the basis for control and supervision activities. This is an invariant trend of time. In the future, effectiveness of investment activities will depend on how much the aggregate of new instruments will be effectively integrated into the economic processes of government and business entities.

\section{Results}

An analysis of the directions for improving control and supervision activities shows active implementation of new generation management systems. They are mainly proposed at the state level. Here is the need to improve the efficiency of capital investment development, provided that the sources of funds are extremely centralized, and work performance and management of the investment cycle are in contrast decentralized. The scale of such dispersion is unparalleled at the level of individual industries and fields of activity. State investments are being appropriated in every constituent entity of the Russian Federation and the municipality, and hundreds of developers and customer services, technical supervision services, etc. are involved. No major corporation has such a large scale of activity. The exception may be transnational corporations (TNCs), but in fact there are very few such forms of doing business in our country.

Due to the logical connection of management systems in TNCs and the state mechanism of capital investments, where the Ministry of Construction and Housing and Communal Services of the Russian Federation currently plays a key role, we note the following. The subject and municipal authorities should have a good command of the communication system in order to ensure a complete understanding of all information flows between the federal level (the Ministry of Construction of Russia, etc.) and budget administrators. An analysis of the directions of the reform of control and supervision activities shows that a lot of work is being performed in this field, and this is consistent with the principles of organizing large business.

So, the results obtained on the basis of the author's analysis have shown that modern and prospective fields of control and supervision activities should be based on a serious analytical basis. Now there are really new opportunities for collecting and studying various information and data generated due to the active introduction of information technologies in the system of public administration. The scheme shown in Fig. 1 clearly indicates that the Internet, various information technologies are now envisaged in almost all measures in the field of control activities.

\section{Discussions}

The issues of increasing the efficiency of investment and construction activities are still extremely urgent. Many researchers at the same time point to the need to develop special measures precisely at the level of the bodies of sectoral management $[5,6]$. In this regard, the development of communication mechanisms at the state level is indeed in demand. Communication of this level allows managing the efficiency of the construction industry. At the same time, it becomes possible to move on to a new generation of control tools. From the point of view of the debatable aspects, there remains the issue of improving the quality of the regulation of various procedures controlled by the state. New communication technologies do not improve the quality of control and do not prevent violations themselves. Participants in construction activities should function within a certain system of rules. In this regard, it is the improvement of the order that really remains a debatable issue, when the main focus of state programs is on various information technologies. At the same 
time, organization of work to increase the availability of various information, its systematization, ensuring the convenience of working with it will be the key to the success of the reform of control and supervision activities.

\section{Conclusion}

Control and supervision activities in the construction industry require many improvements. At the disposal of the industry, technologies emerge that allow instantaneous reporting of information to various participants, and at the same time, to monitor the current situation at a very high speed. Such opportunities create a strong information flow and complicate the management of the industry. Systematization of information in terms of regulations, rules, procedures will be the most important field of activity of state management bodies in construction.

\section{References}

1. V.S. Kankhva, S.S. Uvarova, S.V. Belyaeva, Procedia Engineering, 165, 1046-1051 (2016)

2. V. Kankhva, D. Silka, Procedia Engineering, 165, 1337-1342 (2016)

3. D.N. Silka, MATEC Web of Conferences, 07012 (2016)

4. N. Yaskova, Bulletin of the Irkutsk State Technical University, 1(60), 178-186 (2012)

5. R.S. Golov, V.V. Shilov, S.A. Silantiev, ASEE International Forum, 20766 (2017)

6. N. Yaskova, T. Alexeeva, MATEC Web of Conferences, 07025 (2016) 